\title{
The Weakening Relationship Between ENSO and the Following Summer East Asia-Pacific Teleconnection Since the Late 1990s
}

\section{Xiaojuan Wang ( $D$ mouse0903@126.com )}

Changshu Institute of Technology https://orcid.org/0000-0003-0918-5286

\section{Zeng-Zhen Hu}

NCEP/NWS/NOAA, College Park

$\mathrm{Po} \mathrm{Hu}$

National Climate Center

Jintao Ye

National Climate Center

Guolin Feng

Yangzhou University

\section{Research Article}

Keywords: Weakening relationship, EAP teleconnection, El Niño-Southern Oscillation, Indian Ocean capacitor effect, Northwest Pacific anticyclone

Posted Date: January 31st, 2022

DOI: https://doi.org/10.21203/rs.3.rs-1288167/v1

License: (c) (i) This work is licensed under a Creative Commons Attribution 4.0 International License.

Read Full License 


\section{Abstract}

The predictability and variability of extratropical climate are largely associated with tropical forcing through various teleconnections. The East Asia-Pacific/Pacific-Japan (EAP/PJ) teleconnection is one the most important factors affecting the summer climate in East Asia. In this work, we confirm the weakening relationship between the El Niño-Southern Oscillation (ENSO) and the following summer EAP/PJ teleconnection after the late 1990s and diagnose the characteristics and possible causes with reanalysis and analysis data. The results show that compared with that during 1981-1998, ENSO is less conducive to the formation of anomalous anticyclones in the following summer in the Northwest Pacific and the northward-transmitted Rossby wave train from the Northwest Pacific during 2000-2017, resulting in a weaker summer EAP teleconnection. Meanwhile, variation of ENSO feature since 2000 with a suppressed variability leads to a weakened response in the tropical Indian Ocean in the spring and summer. The reduced sea surface temperature response in the tropical Indian Ocean suppresses the excitation of eastward-propagating Kelvin waves and declines the capacitor effect of the Indian Ocean, which are unfavorable for generating anomalies in the Northwest Pacific and motivate strong EAP teleconnection in meridional direction. Thus, the weakening relationship of ENSO-EAP after late 1990s is the result of the interactions of the suppressed ENSO variability and declined Indian Ocean capacitor effect.

\section{Introduction}

The predictability of extratropical land climate is mainly attributed to various teleconnections forced by tropical forcing. In East Asia, the East Asia Pacific/Pacific-Japan (EAP/PJ) teleconnection is one of the most important teleconnections influencing the summer climate through affects the Okhotsk blocking high and the Meiyu front in East Asia and the Northwest Pacific anomalous anticyclone front (Huang, 1987; Nitta, 1987). When the sea surface temperature (SST) in the Western Pacific Warm Pool is abnormally low in summer, the convective activities near the Philippine region are suppressed, and the "+ +" EAP teleconnection wave train is triggered, resulting in above-normal rainfall in the Jianghuai Basin (the plain between the Yangtze and Huai Rivers), the southern part of the Korean Peninsula and southern Japan, and below-normal rainfall in the lower and higher latitudes(Nitta and $\mathrm{Hu}, 1996)$. Meanwhile, the EAP teleconnection also plays an important role in influencing a north-south reversed "seesaw pattern" of surface air temperature in East Asia(Chen et al., 2016). Moreover, East Asian summer climate variability is largely controlled by both zonal and meridional teleconnection patterns. The zonal one represents a wave train across the Eurasian continent, and the meridional one is the EAP teleconnection(Gong et al., 2018). In fact, the predictability of the eastern Asian summer climate is mainly connected with the EPA/PJ-like teleconnection pattern(Kosaka et al., 2012; Kosaka and Nakamura, 2006). Thus, the variability of EPA/PJ teleconnection is crucial for East Asian summer climate variability and predictability.

It was argued that the formation of the EAP teleconnection mainly links to the south-to-north moving Rossby waves which are triggered by convective activities in the Northwest Pacific Ocean and anticyclonic anomalies in the Philippines as well as atmospheric internal dynamical processes (Choi et al., 2010; Lu et al., 2006; Lu, 2001; Lu and Lin, 2009; Nitta and Hu, 1996; Wang and Zhang, 2002). The 
convective activities in the Northwest Pacific Ocean and anti-cyclonic anomalies in the Philippines are associated with the El Niño-Southern Oscillation (ENSO) (Huang and Wu, 1989; Jin et al., 2016).

Furthermore, in addition to the impact of the Pacific Ocean, the Indian Ocean also plays an important role. For example, in the summer of the El Niño decaying year, the tropical Indian Ocean warms up with enhanced local convective activities and anomalous dispersion in the upper troposphere, triggering warm Kelvin waves to propagate eastward into the tropical western Pacific. Meanwhile, the abnormal convergent sinking appears in the west side, suppressing the convective activities in the Northwest Pacific and thus stimulating the EAP teleconnection wave train that propagates from low latitudes to the North Pole along the coast of East Asia (Li et al., 2008; Xie et al., 2009). Therefore, both ENSO and the Indian Ocean may affect the variability of the following summer EAP teleconnection.

As the strongest interannual signal in the tropical Pacific, ENSO also features significant interdecadal variations, such as the regime shifts in the late 1970s and late 1990s(Duan et al., 2004; Hu et al., 2016; Hu et al., 2020; Hu et al., 2013; Li and Lu, 2020; McPhaden, 2012; Xiang et al., 2013). For example, after the late 1970s, ENSO variability and period increased (Wang, 1995). An opposite shift occurred after the late 1990s with suppressed variability and enhanced frequency of ENSO, the increased east-west SST gradient in the equatorial Pacific, the enhanced Walker circulation, and the weakening of sea-air coupling in the tropical Pacific (Hu et al., 2020; McPhaden, 2012; McPhaden and Luebbecke, 2014). The EAP teleconnection pattern has obvious intraseasonal and interannual variability (Huang, 2004; Huang and Sun, 1992; Li and Chou, 2003; Wu et al., 2009). In recent years, studies revealed, accompanied by regime shifts observed in the East Asian summer monsoon (Huang et al., 2012), the EAP teleconnection also exists the interdecadal variation feature. i.e., Hong et al. (2014) and Wang et al. (2020) revealed that the EAP teleconnection also underwent an interdecadal adjustment in the mid-1990s; Xu et al. (2019) suggested that the PJ pattern obviously shifts eastward during 1999-2015 and the intensity of its barotropic structure in the extratropic weakens significantly. Li and Lu (2020) identified a breakdown of close tropical-extratropical relationships in light of both circulation and rainfall anomalies over the western North Pacific and East Asia. Although it is revealed ENSO-PJ relationship (Kubota et al., 2016) and ENSO's impact on summer rainfall in eastern China (Sun et al., 2021) varies on interdecadal time scales, it is still unclear the confidence and physical mechanism of an interdecadal adjustment of the ENSO-EAP connection after the 1990s. In this work, we try to dig out the variation of ENSO's impact on EAP teleconnection after late 1990s and try to answer (1) if there is significant shift of connection between ENSO and EAP after late 1990s; (2) there are any new features of ENSO's impact on the following summer EAP teleconnection after the late 1990s; (3) what the roles of Indian Ocean are in influencing the interdecadal variation of the summer EAP teleconnection. This paper is organized as the following. Section 2 introduces the data and methods. Section 3 examines the interdecadal variations of the relationship between ENSO and the following summer EAP teleconnection before and after the late 1990s. Section 4 investigates the mechanism for the interdecadal variations. Section 5 analyzes the role of the Indian Ocean in the interdecadal variation of the relationship between ENSO and the following summer EAP teleconnection. Finally, a summary is given in section 6 . 


\section{Data And Methods}

The data used in this paper is from the global monthly reanalysis for June 1979 to August 2017 released by the National Center for Environmental Prediction/National Center for Atmospheric Research (NCEP/NCAR), United States. The variables analyzed in this work include monthly means of geopotential height, wind, vertical velocity, and sea level pressure (SLP) with a resolution of $2.5^{\circ} \times 2.5^{\circ}$. Sea surface temperature (SST) is from version-5 of the Extended Reconstructed for 1979-2017 (NOAA ERSSTv5) with a resolution of $2^{\circ} \times 2^{\circ}$. ENSO is defined based on the Niño 3.4 index from the NOAA Climate Prediction Center (CPC).

The EAP teleconnection index () is calculated according to the definition of Huang (2004):

$$
\mathrm{I}_{\mathrm{EAP}}=-\frac{1}{4} \mathrm{Z}^{*}\left(20^{\circ} \mathrm{N}, 125^{\circ} \mathrm{E}\right)+\frac{1}{2} \mathrm{Z}^{*}\left(40^{\circ} \mathrm{N}, 125^{\circ} \mathrm{E}\right)-\frac{1}{4} \mathrm{Z}^{*}\left(60^{\circ} \mathrm{N}, 125^{\circ} \mathrm{E}\right)
$$

In formula (1), $Z^{\star}$ represents the normalized monthly mean geopotential height anomaly at $500 \mathrm{hPa}$. The analysis methods include synthetic, sliding correlation, regression, and empirical orthogonal function (EOF) analysis. The winter refers to December to February of the following year, while spring from March to May of that year, and summer from June to August of that year.

\section{Weakened Correlations Between Enso And Eap Teleconnection}

Figure 1(a) presents the time series of the proceeding winter Niño 3.4 index and the following summer EAP teleconnection index during 1979-2017. It can be seen that both EAP and ENSO indices have a quasi2-3a periodicity, and the correlation coefficient between ENSO and EAP reaches -0.30 , passing the $95 \%$ significance level. The correlation experienced an interdecadal variation. Figure 1(b) shows the 21-year sliding correlation between the Niño 3.4 and EAP indices. The correlation has weakened since the early 1990s, and it is lower than the $95 \%$ significance level after the late 1990s. Taking 19-year and 15-year sliding correlation respectively, the results are similar (Fig. omitted). In the following, the similarity and difference of ENSO's impact on the following summer EAP teleconnection between periods1981-1998 and 2000-2017 are examined.

Figure 2 shows the first spatial mode (EOF1) and corresponding principal component (PC1) unfolded by empirical orthogonal function (EOF) on summer $500 \mathrm{hPa}$ geopotential height in the two periods. During 1981-1998, EOF1 was a " -+- " tripole pattern from north to south, with anomalous centers mainly located in the eastern Siberia, Northeastern Asia, the northwestern Pacific (Fig. 2a), with the contribution variance of $32.9 \%$. Compared to that in 1981-1998, EOF1 during 2000 - 2017 is generally a similar tripole pattern, but in addition to the weakening of the negative center in the Northwest Pacific, the negative anomalous center in the eastern Siberia is shifted eastward, while the positive anomalous center is shifted westward to the southeast of Lake Baikal with the explained variance reduced to $28.7 \%$ (Fig. 2b). For the temporal 
variation, the PC1 reflects interannual variation (Fig. 2c, d). The PC1 for both 1981-1998 and 2000-2017 is highly correlated with the EAP index, with correlation coefficients of 0.71 and 0.54 for these two periods, respectively. Thus, PC1 of geopotential height anomaly can be a good alternative to the EAP index (Kosaka and Nakamura, 2006).

The correlations of the winter Niño 3.4 index with PC1 and the EAP index in1981-1998 is -0.48 and -0.49 , respectively, significant at the 0.05 confidence level. The corresponding correlations in 2000-2017 are 0.04 and 0.15 , respectively, insignificant at the 0.05 confidence level. The correlation changes suggest a weakening of the connection of ENSO with EPA teleconnection since the late 1990s.

To compare the corresponding atmospheric circulation anomalies, regressions of the spatial distribution of $850 \mathrm{hPa}$ wind and SLP (surface air temperature and precipitation) anomalies against PC1 and EAP index for 1981-1998 and 2000-2017 are given in Fig. 3 and Fig. 4. Overall, the tripole pattern presents in the two periods. However, compared with that in 1981-1998 (left panel of Figs. 3, 4), the positive center in the Northwest Pacific weakens and is less significant in 2000-2017 (right panel of Figs. 3, 4), although the two anomaly centers in the middle and high latitudes are largely comparable between the two periods. Such difference implies that the connection of the extratropical segment of the EPA teleconnection with the tropical Northwest Pacific has weakened since the late 1990s. That may suggest a decline in the influence of ENSO on the EPA teleconnection.

\section{Change Of Proceeding Enso's Impact On The Following Summer Eap Teleconnection}

Figure 5 shows the regressions of proceeding winter ENSO on the following summer atmospheric circulation in East Asia before and after 1999. For 1981-1998, there are significant correlations between ENSO and the low, middle, and upper troposphere anomalies in the East Asia monsoon region. In the lower troposphere, ENSO favors positive SLP anomalies in areas such as the Philippines, which is prone to forming anomalous anticyclones in the Northwest Pacific. The EAP teleconnection refers to a Rossby wave train propagating to the mid- and high-latitudes triggered by abnormal convective activity in the tropical Northwest Pacific that is associated with ENSO, which further influences the circulation system over East Asia. For example, at the lower and middle troposphere (Fig. 5a, C, e), ENSO is likely to lead to anomalous positive height and enhanced sinking motions at the low latitude of the Northwest Pacific and the Sea of Okhotsk, anomalous negative and enhanced rising motion in Japan. Similarly, at $200 \mathrm{hPa}$ (Fig. $5 \mathrm{~g}$ ), the vorticity anomalies are negative in the northeast region of Lake Baikal and the tropical Northwest Pacific and positive in between, favoring the formation of the "anticyclone-cyclone-anticyclone" triple structure over East Asia.

In contrast, the triple pattern in East Asia in 2000-2017 (right panels of Fig. 5) is less distinct than in 19811998 (left panels of Fig. 5), meaning a weakened impact of ENSO on the summer EAP teleconnection. Compared with the regressions in the mid-and high latitudes, the differences between the two periods are more pronounced for the regressions in the tropical Northwest Pacific. For example, the regressions are 
mostly significant in the tropical Northwest Pacific in 1981-1998 and insignificant in 2000-2017, especially in the lower and upper troposphere. That is consistent with the results shown in Figs. 3 and 4.

Table 1 The El Nio and La Nia years in the periods of 1981-1998 and 2000-2017.

\begin{tabular}{|lll|}
\hline & $1981-1998$ & $2000-2017$ \\
\hline El & $1982 / 83,1986 / 87,1987 / 88,1991 / 92$, & $2002 / 03,2004 / 05,2006 / 07,2009 / 10$, \\
Nio & $1994 / 95,1997 / 98$ & $2014 / 15,2015 / 16$ \\
\hline La & $1984 / 85,1988 / 89,1995 / 96$ & $2000 / 01,2007 / 08,2010 / 11,2011 / 12$ \\
Nia & & \\
\hline
\end{tabular}

When warm (cool) SST anomalies are observed in the equatorial central and eastern Pacific, the convection activity over the equatorial central Pacific is enhanced (suppressed), and the zonal wind stress and upwelling in the equatorial eastern Pacific weaken (strengthens), then warm (cool) SST anomalies amplify. That is referred to as the Bjerknes feedback (Bjerknes 1969). Through generating a Gill-like response (Gill 1980), ENSO affects the East Asian summer climate by modulating the Western Pacific subtropical high and rainfall belt in Eastern China (Wang et al. 2000; Wang and Zhang 2002). To further examine the influence of ENSO, El Niño and La Niña year composites are shown in Fig. 6. The El Niño (La Niña) years denote that the Niño3.4 index is above (below) 0.5 times of standard deviation are selected (Table 1).

Consistent with the regressions shown in Figs. 3-5, the anomalies in East Asia and the Northwest Pacific during 2000-2017 are weaker for both El Niño and La Niña year composites than that during 1981-998 (Fig. 6). Compared with the pronounced tripole pattern associated with the EPA teleconnection during 1981-1998 (Fig. 6a, b), the tripole pattern is less distinct during 2000-2017 (Fig. 6c, d). Thus, during 1981 1998, ENSO was favorable to the formation of the EAP teleconnection pattern, while during $2000-2017$, the role of ENSO in triggering the EAP teleconnection was significantly weakened. Such change may be partially associated with the interdecadal shift of the ENSO regime. Since 2000, tropical Pacific variability is suppressed, ENSO frequency and the east-west SST gradient in the equatorial Pacific increase, the Walker circulation strengthens, and the sea-air coupling in the tropical Pacific is weakened and shifted westward (Hu et al., 2013; Li et al., 2019; McPhaden, 2012). In addition to the Pacific, the Indian Ocean may also contribute to the interdecadal change of the EAP teleconnection.

\section{Role Of The Northwest Pacific And Indian Oceans}

This section examines the role of the Northwest Pacific and Indian Oceans in the weakening of the influence of ENSO on the EAP teleconnection since the late 1990s. During both 1981-1998 and 20002017, the SST anomalies with the anomalous warm (cold) SST in the equatorial central and eastern Pacific and the anomalous cold (warm) SST in the western Pacific associated with El Niño (La Niña) persist into spring (Fig. 7). However, compared with that in 1981-1998 (Fig. 7c, e), the positive regression center over the equatorial Pacific extends further westward in both spring and summer in 2000-2017 
(Fig. 7d, f). That is consistent with the westward shift of the atmosphere-ocean coupling in the tropical Pacific since 2000 and frequency increase of the central Pacific (CP) ENSO (Li et al., 2019; Yeh et al., 2009). In addition to the tropical Pacific, the lag connection of ENSO with Indian Ocean SSTAs in the following summer weakened during 2000-2017 compared with that during 1981-1998 (Fig. 7e, f). That means that the capacitor effect of the Indian Ocean in transferring the ENSO impact on East Asian summer climate variability has declined during 2000-2017 (Xie et al., 2009).

Figure 8 shows the distribution of Walker circulation regressed onto the proceeding winter Niño3.4 index. Compared with that in 1981-1998 (Fig. 8a, C), ENSO was associated with weaker Walker circulation anomalies: weaker ascending (descending) anomalies in proceeding winter and following spring over the equatorial central and eastern (western) Pacific in 2000-2017 (Fig. 8b, d). To further examine the interdecadal variation of the connection of ENSO with the Indian Ocean, Fig. 9 shows 21-year moving correlations of the winter Niño3.4 index with $\mathrm{I}_{\mathrm{TIO}}$ in the following spring and summer. The correlations with the following spring $I_{T I O}$ are positive, stable, and significant. However, the correlations with the following summer $\mathrm{I}_{\mathrm{T} O \mathrm{O}}$ are positive and significant before the mid-1990s, then weaken rapidly and become insignificant (Fig. 9). These results suggest a weakening of the influence of ENSO on the following summer Indian Ocean.

In addition to the interdecadal variation of the influence of ENSO on the Indian Ocean, the impact of the Indian Ocean on the Northwest Pacific and East Asia displayed an interdecadal variation. Figure 10 shows the regressions of summer circulation anomalies onto spring $\mathrm{I}_{\mathrm{T} O \mathrm{O}}$ in the two periods. It is seen that the EAP-like tripole teleconnection pattern in the Northwest Pacific and East Asia is more significant in 1981-1998 compared with that in 2000-2017. Especially, during 2000-2017 (Fig. 10b, d), the EAP-like tripole pattern became vague, implying that the role of the Indian Ocean in triggering the EAP-like teleconnection pattern in East Asian summer was declined during 2000-2017.

In summary, the lagged impact of ENSO on the Indian Ocean in summer weakened after the late 1990s. This may be due to the weakening of ENSO variability and atmosphere-ocean coupling in the tropical Pacific since 2000 (Hu et al., 2013). Through the reduced Walker circulation anomalies, the lagged response of the Indian Ocean to ENSO weakened in winter and spring. The weakened response of the Indian Ocean to ENSO in 2000-2017 reduces the capacitor effector of the Indian Ocean in ENSO decay summer in influencing the western Pacific subtropical high via generating eastward-propagating Kelvin waves (Xie et al., 2009). As a result, the EPA teleconnection weakened in 2000-2017.

\section{Conclusions}

This study noted a weakened relationship between the proceeding winter ENSO and the following summer EAP teleconnection and examined the roles of ENSO and the Indian Ocean in the interdecadal variation of the relation. The main conclusions are summaries as the followings as well as the schematic diagram of Fig. 11: 
(1) In the late 1990s, the relationship between the proceeding winter ENSO and the following summer EAP teleconnection weakened significantly. Compared with that in 1981-1998, the triple pattern was less distinct in 2000-2017. The weakening of the teleconnection is especially pronounced for the active center in the tropical Northwest Pacific.

(2) The interdecadal variation of the relationship between the proceeding winter ENSO and the following summer EAP teleconnection may be associated with the interdecadal shift of ENSO features around 1999/200, including suppression of the variabilities of ENSO and the atmosphere-ocean coupling in the tropical central and eastern Pacific were suppressed and increase of the ENSO frequency. The weakened ENSO variability led to reduced responses in the tropical Northwest Pacific and Indian Oceans.

(3) The weakened response of the Indian Ocean to ENSO in 2000-2017 declined the capacitor effect of the Indian Ocean in ENSO decay summer in influencing the western Pacific subtropical high via generating eastward-propagating Kelvin waves. As a result, the summer anomalies in the tropical Northwest Pacific induced by the Indian Ocean through the capacitor effect in the ENSO decay summer were small, leading to the weakening of the EPA teleconnection in 2000-2017.

\section{Declarations}

Acknowledgments. This work was supported by the National Key Research and Development Program of China (2017YFC1502306), the National Natural Science Foundation of China Project (41875100, 42075057 and 42130610).

Data Availability Statement. The datasets generated during and/or analyzed during the current study are available from the corresponding author on reasonable request.

\section{References}

1. Chen W, Hong X, Lu R, Jin A, Jin S, Nam J-C, Shin J-H, Goo T-Y, Kim B-J (2016) Variation in summer surface air temperature over Northeast Asia and its associated circulation anomalies. Advances in Atmospheric Sciences 33:1-9 DOl:https://doi.org/10.1007/s00376-015-5056-0

2. Choi K-S, Wu C-C, Cha E-J (2010) Change of tropical cyclone activity by Pacific-Japan teleconnection pattern in the western North Pacific. Journal of Geophysical Research 115:1-13 DOl:https://doi.org/10.1029/2010JD013866.

3. Duan W, Mu M, Wang B (2004) Conditional nonlinear optimal perturbations as the optimal precursors for El Nino-Southern Oscillation events. Journal of Geophysical Research: Atmospheres 109:1-12 DOl:https://doi.org/10.1029/ 2004JD004756.

4. Gong Z, Feng G, M. D, Huang G (2018) The Possible Physical Mechanism for the EAP-SR co-action. . Clim. Dyn. 51: 1499-1516 DOl: https://doi.org/10.1007/ s00382-017-3967-4.

5. Hong CC, Chang TC, Hsu HH (2014) Enhanced relationship between the tropical Atlantic SST and the summertime western North Pacific subtropical high after the early 1980s. Journal of Geophysical 
Research: Atmospheres 119:3715-3722.

6. Hu Z-Z, Kumar A, Huang B (2016) Spatial distribution and the interdecadal change of leading modes of heat budget of the mixed-layer in the tropical Pacific and the association with ENSO. Climate Dynamics 46:1753-1768 DOl:https://doi.org/ 10.1007/s00382-015-2672-4.

7. Hu Z-Z, Kumar A, Huang B, Zhu J, L’Heureux M, McPhaden MJ, Yu J-Y (2020) The interdecadal shift of ENSO properties in 1999/2000: A review. Journal of Climate 33:4441-4462 DOI:https://doi.org/10.1175/JCLI-D-19-0316.1.

8. Hu Z-Z, Kumar A, Ren H-L, Wang H, L'Heureux M, Jin F-F (2013) Weakened interannual variability in the tropical Pacific Ocean since 2000. Journal of Climate 26:2601-2613

DOI:https://doi.org/10.1175/JCLI-D-12-00265.1.

9. Huang G (2004) An Index Measuring the Interannual Variation of the East Asian Summer MonsoonThe EAP Index. Adv. Atmos. Sci. 21:41-52 DOl:https:// doi.org/10.1007/BF02915679.

10. Huang R Influence of the heat source anomaly over the tropical western Pacific on the subtropical high over East Asia. in International Conference on the General Circulation of East Asia, Chengdu, pp. 40-51.

11. Huang R, Liu Y, Feng T (2012) Interdecadal change of summer precipitation over Eastern China around the late-1990s and associated circulation anomalies, internal dynamical causes. Chinese Science Bulletin 58:1339-1349 DOI:10.1007/s11434 -012-5545-9.

12. Huang R, Sun F (1992) Impacts of the tropical western Pacific on the East Asian summer monsoon. Journal of the Meteorological Society of Japan 70:243-256

DOI:https://doi.org/10.2151/jmsj1965.70.1B_243.

13. Huang R, Wu Y (1989) The influence of ENSO on the summer climate change in China and its mechanism. Advances in Atmospheric Sciences 6:21-32 DOI:https://doi.org/10.1007/BF02656915.

14. Jin D, Hameed SN, Huo L (2016) Recent changes in ENSO teleconnection over the western Pacific impacts the eastern China precipitation dipole. Journal of Climate 29:7587-7598 DOI:https://doi.org/10.1175/JCLI-D-16-0235.1.

15. Kosaka Y, Chowdary JS, Xie S, Min Y, Lee J (2012) Limitations of Seasonal Predictability for Summer Climate over East Asia and the Northwestern Pacific. Journal of Climate 25:7574-7589 DOI:https://doi.org/10.1175/JCLI-D-12-00009.1.

16. Kosaka Y, Nakamura H (2006) Structure and dynamics of the summertime Pacific-Japan teleconnection pattern. Quarterly Journal of the Royal Meteorological Society 132:2009-2030 DOl:https://doi.org/10.1256/qj.05.204.

17. Kubota H, Kosaka Y, Xie SP (2016) A 117-year long index of the Pacific-Japan pattern with application to interdecadal variability. International Journal of Climatology 36:1575-1589.

18. Li H, Dai A, Zhou T, Lu J (2008) Responses of East Asian summer monsoon to historical SST and atmospheric forcing during 1950-2000. Climate Dynamics 34:501-514 DOI:10.1007/s00382-0080482-7. 
19. Li J, Chou J (2003) Global analysis theory of climate system and its applications. Chinese Science Bulletin 48:1034-1039 DOl:https://doi.org/10.1007/BF03184222.

20. Li X, Hu Z-Z, Becker E (2019) On the westward shift of tropical Pacific climate variability since 2000. Climate Dynamics 53:2905-2918 DOI:https://doi.org/ 10.1007/s00382-019-04666-8

21. Li X, Lu R (2020) Breakdown of the summertime meridional teleconnection pattern over the western North Pacific and East Asia since the early 2000s. Journal of Climate 33:8487-8505.

22. Lu R, Li Y, Dong B (2006) External and internal summer atmospheric variability in the western North Pacific and East Asia. Journal of the Meteorological Society of Japan 84:447-462 DOl:https://doi.org/10.2151/jmsj.84.447

23. Lu RY (2001) Atmospheric circulations and sea surface temperatures related to the convection over the western Pacific warm pool on the interannual scale. Adv Atmos Sci 18:270-282 DOI: https://doi.org/10.1007/s00376-001-0019-z

24. Lu RY, Lin ZD (2009) Role of subtropical precipitation anomalies in maintaining the summertime meridional teleconnection over the western North Pacific and East Asia. Journal of Climate 22:20582072 DOl:https://doi.org/10.1175/ 2008JCLI2444.1.

25. McPhaden M (2012) A 21 st century shift in the relationship between ENSO SST and warm water volume anomalies. Geophysical research letters 39:1-5 DOI:https://doi.org/10.1029/2012GL051826.

26. McPhaden M, Luebbecke $J$ (2014) Assessing the 21 st century shift in ENSO variability in terms of the Bjerknes stability index. Journal Of Climate 27:2577-2587 DOI: https://doi.org/10.1175/JCLI-D13-00438.1.

27. Nitta T (1987) Convective activities in the tropical western Pacific and their impact on the Northern Hemisphere summer circulation. Journal of the Meteorological Society of Japan 65:373-390 DOI:https://doi.org/10.2151/jmsj1965.65.3_373.

28. Nitta T, Hu Z (1996) Summer climate variability in China and its association with. J Meteorol Soc Jpn 74:425-445 DOl:https://doi.org/10.2151/jmsj1965.74.4_425

29. Sun L, Yang X-Q, Tao L, Fang J, Sun X (2021) Changing Impact of ENSO Events on the Following Summer Rainfall in Eastern China since the 1950s. Journal of Climate 34:8105-8123.

30. Wang B (1995) Interdecadal changes in El Nino onset in the last four decades. Journal of Climate 8:267-285 DOl:https://doi.org/10.1175/1520-0442(1995)008 <0267:ICIENO>2.0.C0;2.

31. Wang B, Zhang Q (2002) Pacific-east Asian teleconnection. Part II: How the Philippine Sea anomalous anticyclone is established during El Nino development. Journal of climate 15:3252-3265 DOl:https://doi.org/10.1175/1520-0442(2002) 015<3252:PEATPI>2.0.C0;2.

32. Wang Z, Wen Z, Chen R, Li X, Huang S (2020) Interdecadal enhancement in the interannual variability of the summer monsoon meridional circulation over the South China Sea around the early 1990s. Climate Dynamics 55:2149-2164 DOl:https://doi.org/10.1007/s00382-020-05375-3.

33. Wu Z, Wang B, Li J, Jin FF (2009) An empirical seasonal prediction model of the East Asian summer monsoon using ENSO and NAO. Journal of Geophysical Research: Atmospheres 114 DOI: https://doi.org/10.1029/2009JD011733

Page 10/16 
34. Xiang B, Wang B, Li T (2013) A new paradigm for the predominance of standing central Pacific warming after the late 1990s. Climate Dynamics 41:327-340 DOl:https://doi.org/10.1007/s00382012-1427-8.

35. Xie S, Hu K, Hafner J, Tokinaga H, Du Y, Huang G, Sampe T (2009) Indian Ocean Capacitor Effect on Indo-Western Pacific Climate during the Summer following EI Niño. Journal of Climate 22:730-747 DOI:https://doi.org/10.1175/ 2008JCLI2544.1.

36. Xu P, Wang L, Chen W, Feng J, Liu Y (2019) Structural changes in the Pacific-Japan pattern in the late 1990s. Journal of Climate 32:607-621.

37. Yeh S-W, Kug J-S, Dewitte B, Kwon M-H, Kirtman BP, Jin F-F (2009) El Niño in a changing climate. Nature 461:511-514 DOl:https://doi.org/10.1038/nature08316.

\section{Figures}

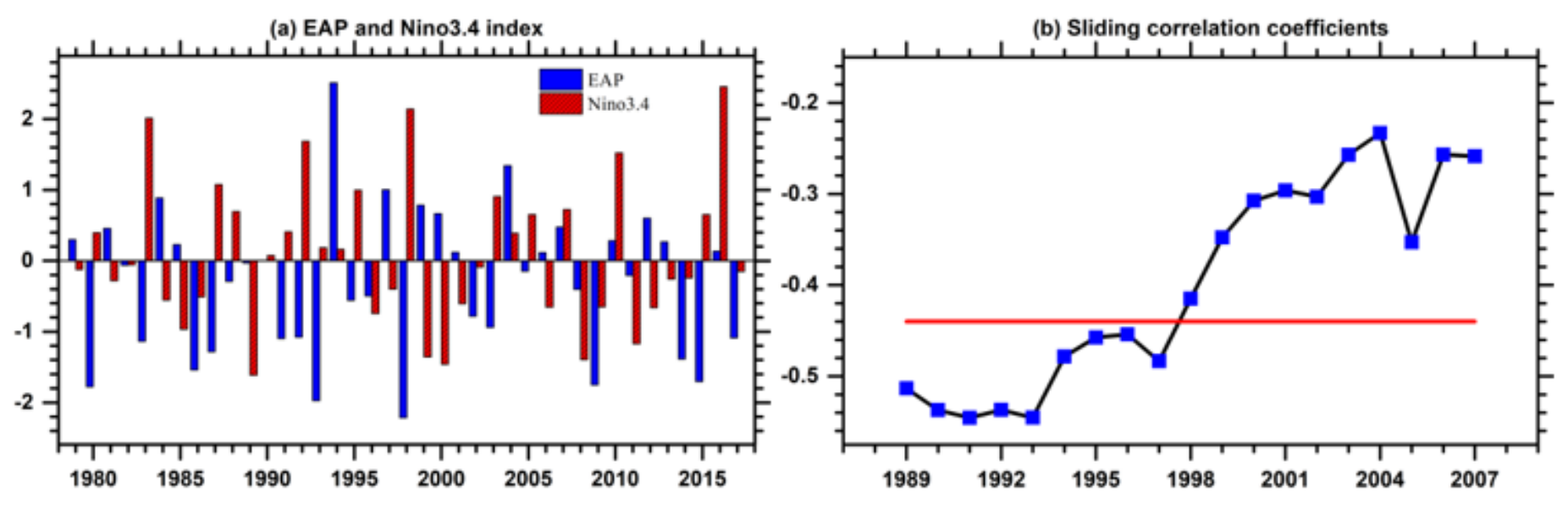

\section{Figure 1}

(a) Time series of proceeding winter Niño3.4 index and following summer EAP index during 1979-2017. Both indices are standardized, and linear trend removed. (b) 21-year sliding correlation coefficients between the Niño3.4 and EAP indices. The red straight line in (b) indicates the 95\% significance level. 

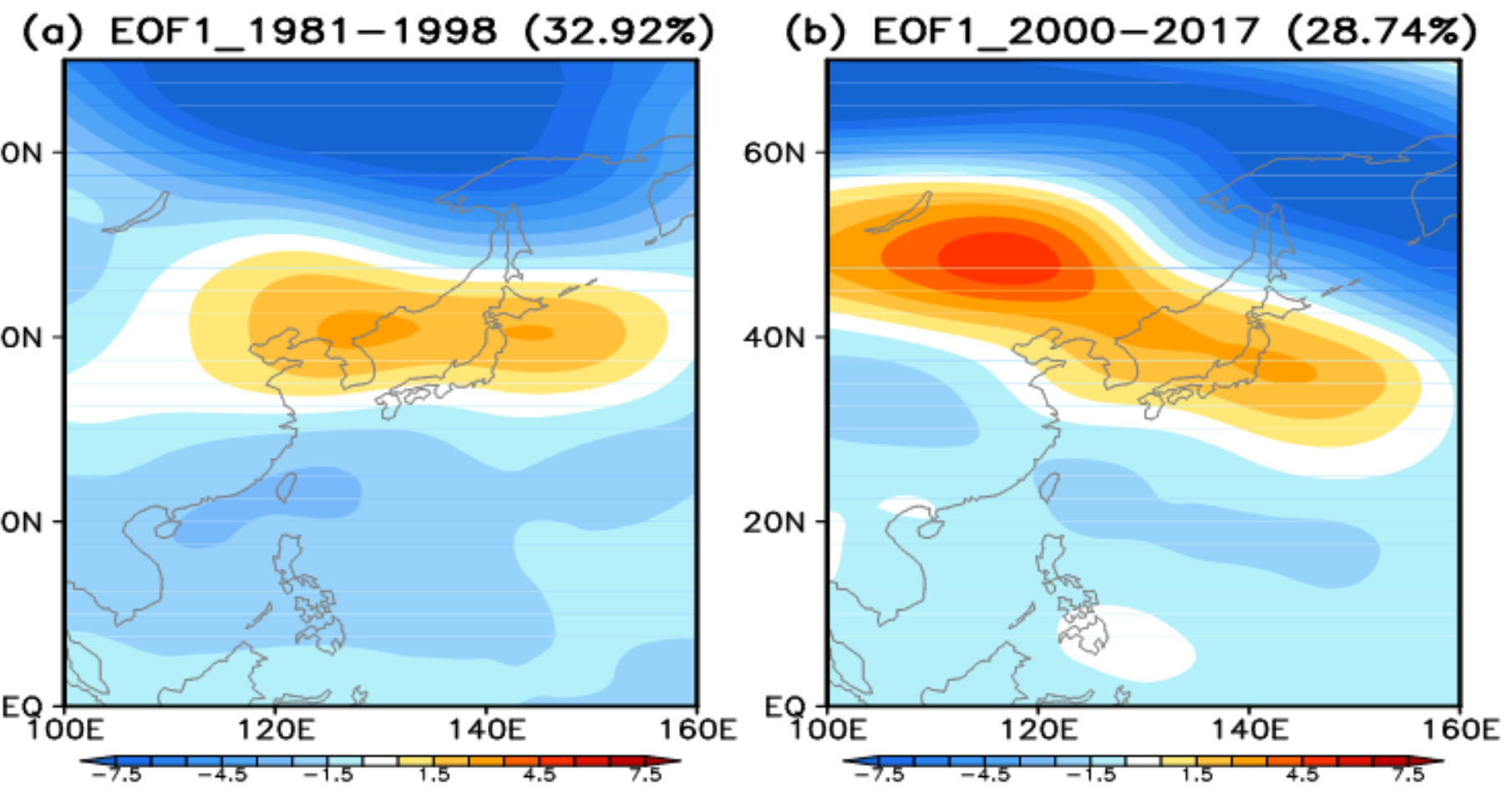

(c) PC1_1981-1998

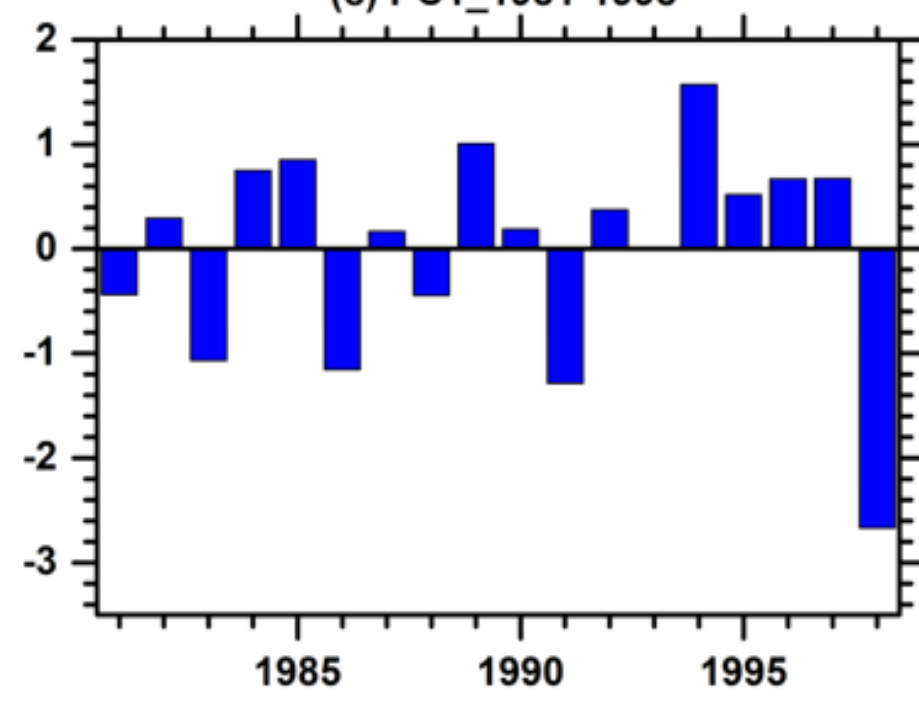

(d) PC1_2000-2017

Figure 2

Spatial distribution ( $a, b)$ spatial mode (EOF1) and (c, d) principal components (PC1) of the first mode derived by EOF of the $500-\mathrm{hPa}$ height in East Asia $\left(100-160^{\circ} \mathrm{E}, 0-70^{\circ} \mathrm{N}\right)$ during the summer of $(\mathrm{a}, \mathrm{c}) 1981-$ 1998; and (b, d) 2000-2017.

Figure 3 
Regressions of anomalous $850 \mathrm{hPa}$ wind (vector, $\mathrm{m} \mathrm{s}^{-1}$ ) and SLP (shade hPa) field against the PC1 $(\mathrm{a}, \mathrm{b}$ ) and EAP index (c, d) for 1981-1998 and 2000-2017, respectively. The dotted area shows the SLP passed the 0.05 confidence level. Only the wind vector passing the 0.05 confidence level is plotted.
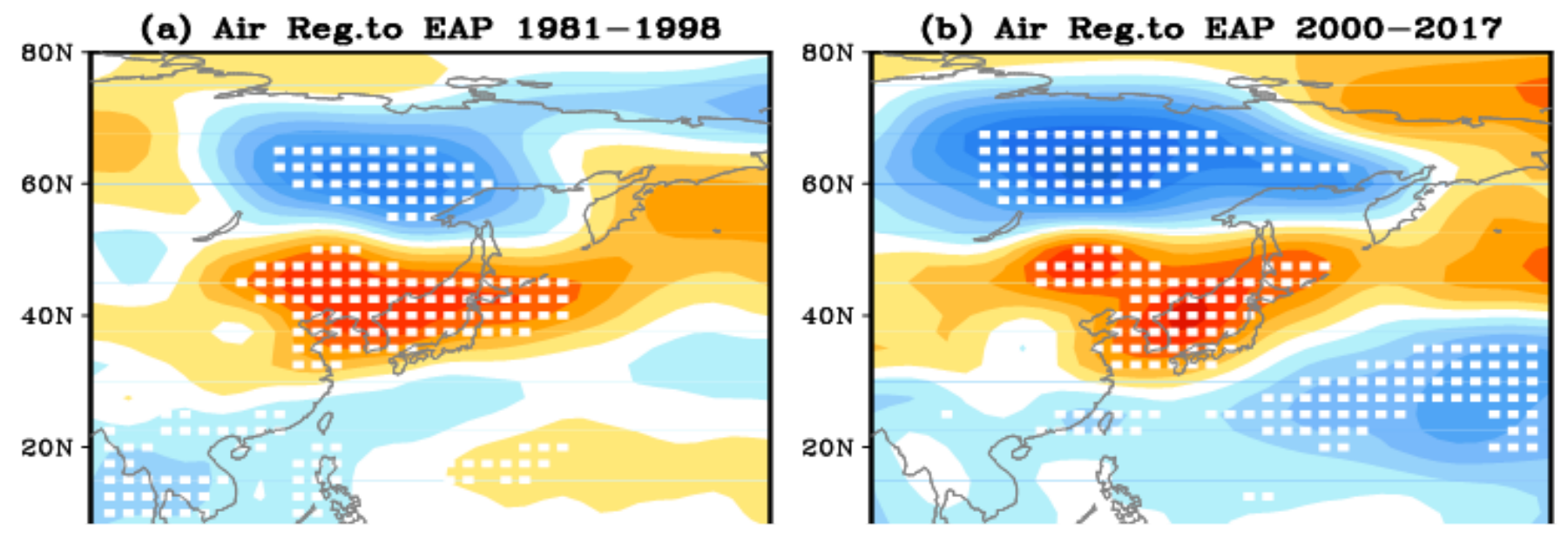

\section{Figure 4}

Regressions of temperature $\left({ }^{[} \mathrm{C}\right)(\mathrm{a}, \mathrm{b})$ and precipitation $(\mathrm{mm})(\mathrm{c}, \mathrm{d})$ anomalies against the EAP index for 1981-1998 (a, c) and 2000-2017 (b, d). The dotted areas indicate the significance at the 0.05 confidence level.

\section{Figure 5}


Regression of summer $(\mathrm{a}, \mathrm{b})$ 850hPa wind (vector, $\mathrm{m} \mathrm{s}^{-1}$ ) and SLP (shade, hPa), (c, d) 500hPa geopotential height (shade, gpm), (e, f) 500hPa vertical velocity (shade, $\times 10^{6} \mathrm{~s}^{-1}$ ), and $(\mathrm{g}, \mathrm{h}$ ) 200hPa wind (vector, $\mathrm{m} \mathrm{s}^{-1}$ ) and vortex field against proceeding winter Niño 3.4 index for the two selected periods. (a, c, e, g) for 1981-1998 and (b, d, f, h) for 2000-2017. The dotted areas indicate the 0.05- confidence level. The wind vector only gives those passed the 0.05 -confidence level.

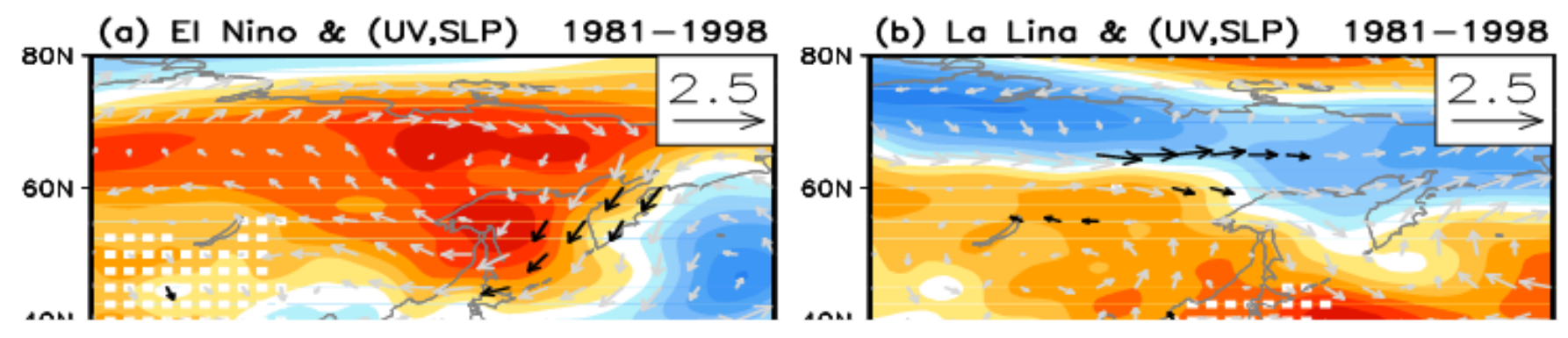

\section{Figure 6}

The composite diagram of $850 \mathrm{hPa}$ wind (vector, $\mathrm{m} \mathrm{s}^{-1}$ ) and SLP anomalies (shaded, gpm) in the El Ni o/ La Ni

a years during two periods. (a, c) for 1981-1998; (b, d) for 2000-2017. The dotted areas indicate SLP passed the 0.05 confidence level, the black arrow indicates wind vector passed the 0.05 confidence level. 
(a) SST_DJF Reg.to nino3.4_DJF_1981-1998

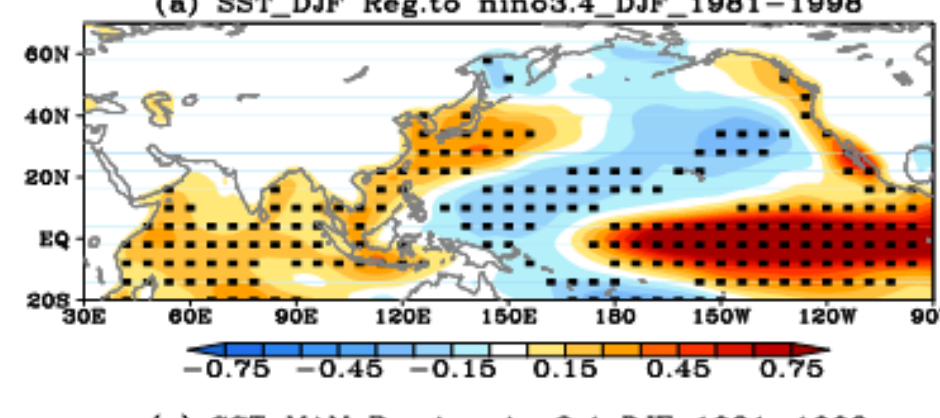

(a) SST MAM Rag to ninna A NIF IOR1-1OQR (b) SST_DJF Reg.to nino3.4_DJF_2000-2017

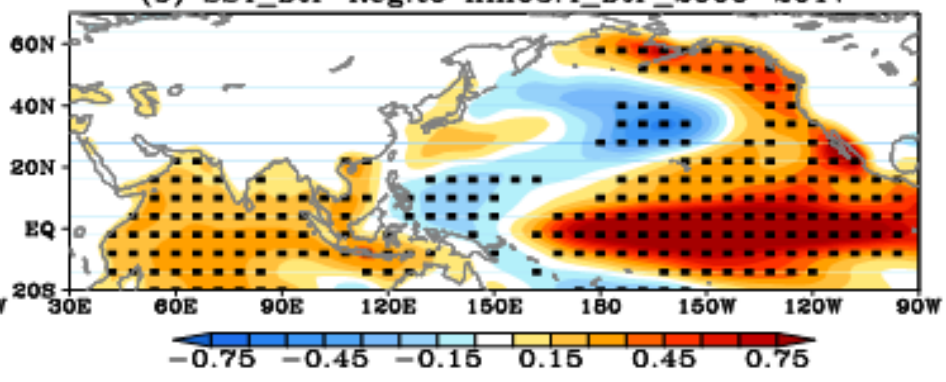

(d) SST MAM Rea to ninna 4 n.FF snnn-2017

\section{Figure 7}

The distribution of SST anomalies $\left({ }^{\mathrm{C}} \mathrm{C}\right)$ regressed onto the winter Niño 3.4 index for winter $(\mathrm{a}, \mathrm{b})$, spring (c, d), and summer (e, f) in the two selected periods, with (a, c, e) for 1981-1998; (b, d, f) for 2000-2017. The dotted indicates the regions that SST passed the 0.05 confidence level test.

\section{Figure 8}

The distribution of the zonal and vertical wind anomalies $\left(\mathrm{m} \mathrm{s}^{-1}\right)$ regressed onto Niño 3.4 index in winter $(a, b)$, spring (c, d), and summer (e, f) in the two periods. (a, c, e) for 1981-1998, (b, d, f) for 2000-2017. The shaded areas indicate the $0.1,0.05$, and 0.01 confidence level, respectively.

\section{Figure 9}

21-year moving correlations of winter Niño 3.4 index with the $\mathrm{I}_{\mathrm{T} O}$ index in following spring (pink dot) and summer (blue triangle) during 1979-2017. 


\section{Figure 10}

Distribution of summer $(\mathrm{a}, \mathrm{b}) 850 \mathrm{hPa}$ wind (vector, $\mathrm{m} \mathrm{s}^{-1}$ ) and SLP (shade, hPa) and (c, d) 500hPa vertical velocity (shade, $\left.\times 10^{6} \mathrm{~s}^{-1}\right)$ and OLR $\left(\mathrm{W} \mathrm{m}^{-2}\right)$ anomalies regressed onto spring $\mathrm{I}_{\mathrm{TIO}}$ in the two periods. $(\mathrm{a}, \mathrm{c})$ for 1981-1998, (b, d) for 2000-2017. The shaded in (a, b, c, d) indicates the regions where SLP and $500 \mathrm{hPa}$ vertical velocity passed the 0.05 confidence level test. Black arrows indicate the 0.05 confidence level of convergent wind $(a, b)$.

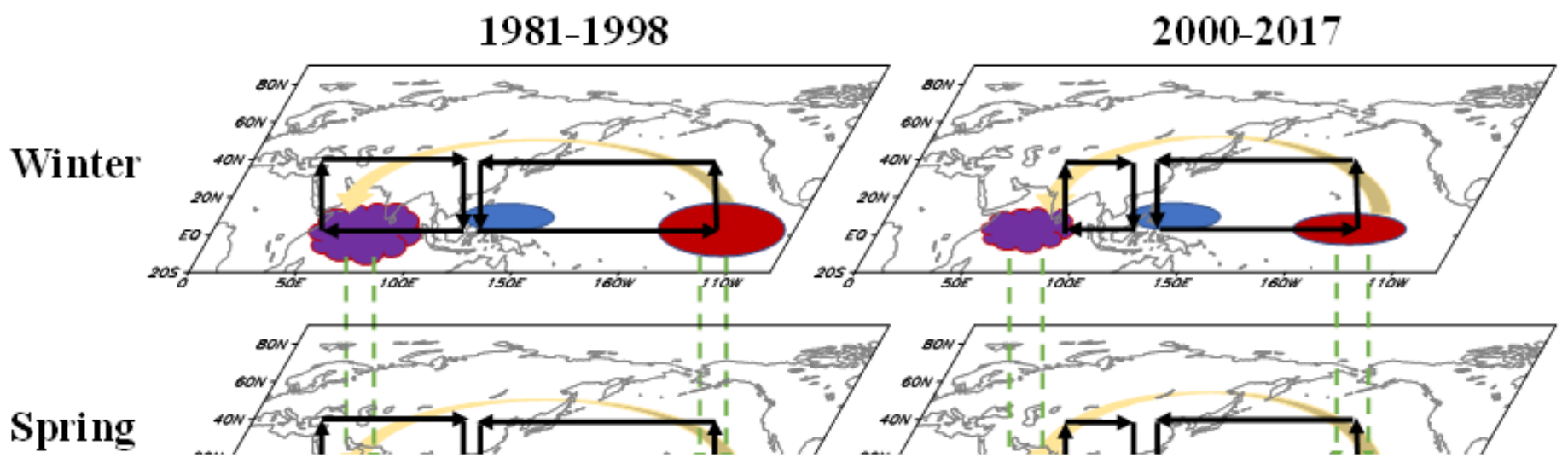

\section{Figure 11}

The schematic diagram of the impact of the proceeding winter ENSO on the following EAP teleconnection. Red and blue ellipses indicate ENSO SST, purple ellipses indicate Indian Ocean SST, orange and green ellipses indicate EAP teleconnection wave trains, and dashed ellipses indicate that the insignificant connection of EAP teleconnection with Indian Ocean SST. 